\title{
Linking Academic Courses with Practical Hands-on Experience for Civil, Environmental and Geological Engineering Students
}

\author{
Chris Muirhead $^{1}$, Rania Al-Hammoud ${ }^{1}$, James R. Craig ${ }^{1}$, and Bruce Macvicar ${ }^{1}$ \\ ${ }^{1}$ Department of Civil and Environmental Engineering, University of Waterloo, Waterloo, Canada \\ Corresponding Author: ralhammo@uwaterloo.ca
}

\begin{abstract}
Civil, environmental and geological engineering students are often disconnected from hands-on activities related to their area of study for the first several years of their degree due to a focus on theory and fundamentals. This can lead to a failure to connect concepts between academic courses as well as high rates of transfer to other programs. This paper will present the implementation of a 2-day 'design days' event where civil, environmental and geological engineering students work in an open setting with a realistic problem they may encounter in future co-op jobs or upon graduation. Preliminary results of student feedback from the most recent design days showed students felt they were able to explore creative solutions to the design problem and have a better understanding of what is involved in an open design process While there was limited reporting of increased motivation in their current courses, they did report that the design days increased the likelihood that they would approach a professor or TA outside of class time or office hours. Overall, every students said they would participate in another similar event, including $46 \%$ stating strongly they would participate again.
\end{abstract}

Keywords: engineering education, problem-based learning, collaborative, cooperative

\section{INTRODUCTION}

Design projects are common for final-year engineering students, however there is limited ability to work on open-ended design projects in the early years of an engineering degree at the University of Waterloo. In addition to the lack of early-year design projects requiring creative solutions, the increasing use of computer modelling has lead to limited opportunity for hands-on activities in Civil, environmental and geological engineering programs. This leads to a regimented style of learning, focussed on academic goals. As stated by Hardiman \& Whitman (2014) "when students focus on mastery of learning rather than performance on tests, they significantly increase their intrinsic motivation for learning". These factors, in addition to a high transfer rate out of environmental and geological engineering programs has led to the introduction of 2-day design days activities for the Civil, environmental and geological engineering undergraduate students at different points in their studies. Examples of other similar events that were introduced in the faculty of engineering at the University of Waterloo are presented in McKay et al., 2016; Ivkovic et al., 2017 and Rennick et al., 2017.

These events focus on providing a collaborative setting for the students where they must work through an open-concept design problem. Working in small groups of 4-5 students allows for teamwork and collaboration with the intention of simulating the creative thought process. As discussed in Duncan \& Dirk (2000), working collaboratively has shown to improve academic results in comparison to working in isolation. The design problem is set up with the intention of replicating a problem similar to something they may work on in the future as a co-op student or an engineering graduate. The problem included design choices where a perfect solution was either not possible or not obvious. It has been found that problem-solving activities which replicate processes of scientists or other professionals result in enhanced learning (Repice et al. 2015). By replicating the nonlinear design process, this problem encouraged both creativity and failure as a part of working towards the best solution possible.

The events included 2 days where the students did not have lectures or deliverables for their second year classes. The events were voluntary and have seen approximately $75 \%$ participation from the students. The events included participation from course professors, teaching assistants (TAs) and local consulting firms as experts either running meetings with the students, hosting presentations or discussing design procedures in an intimate setting. As a general model, the students performed the investigation and design on the first day of the event, followed by construction and testing of their design on the second day of the event. 


\section{2. $2^{\text {nd }}$ YEAR CIVIL ENGINEERING DESIGN DAYS EVENT}

The first series of events were designed for second-year Civil Engineering students where they were required to design a road connecting point $\mathrm{A}$ to point $B$ including the design of a bridge and costing of the entire project. The students were then responsible for building a scale model of the bridge out of polyethylene foam for design days and wood and plastic stir sticks for the course project. The design incorporated components from each of their Mechanics, Materials, Statistics and Probabilities and Economics courses, allowing for the students to complete a comprehensive design process. A diagram of the integration of each of the courses incorporated into the design project is shown in Figure 1

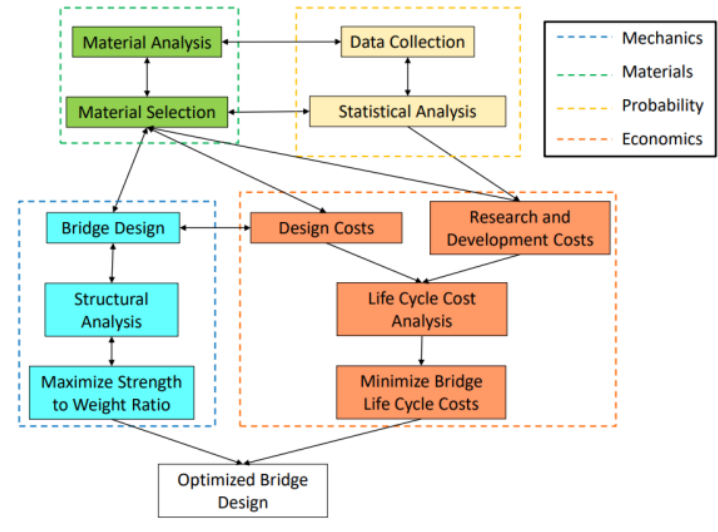

Figure 1: Diagram of integration between the four courses for the Civil Engineering Design Day (Balkos et al., 2017)

During this project the students were responsible for not only designing a bridge to cross the river but also for finding the optimal design solution both in terms of cost and safety. During testing of the bridges, the winning group was the group that had the lowest cost while designing as close as possible to the required strength of the bridge. Over-designs were deducted points as they were not the optimal solution. A more in-depth summary of the results from the $2^{\text {nd }}$ year Civil Engineering Design Day was summarized in Phillips et al. (2018).

\section{SECOND YEAR ENVIRONMENTAL AND GEOLOGIC ENGINEERING DESIGN DAYS EVENT}

The second design day event was developed for the $2^{\text {nd }}$ year Environmental and Geological engineering students with the first event from this series taking place in March of 2018. The scenario presented to the students was a mining company that was expanding production in Northwestern Ontario and required a specified amount of energy to power their production. The company invited bids on a hydroelectric dam to power the mine during operation and then continue to supply energy to the surrounding First Nations communities after mine closure.

The students were required to complete an abbreviated "Stakeholder Consultation" which included meeting with representatives from the client, Department of Fisheries and Oceans (DFO), Ontario Power Generation (OPG) and First Nations (Figure 2). Local consulting engineers volunteered as the client and DFO representative while graduate students volunteered as the representatives from OPG and First Nations. The graduate student consulted with First Nations and was just giving their perspective as they were not able to attend last minute. Each meeting was run as a collaborative session with a brief introduction of the representative, followed by a question and answer period. The representatives had talking points either based on their experience with these agencies or, in the case of the First Nations through consultation. Only one student from each group could attend each session so that the students would decide in advance what information they wished to get out of the consultation session and then report the answers to their group in a clear and concise manner. The final design included determining the precise location of their dam in relation to fish habitat and potential flooding damage during the creation of the reservoir. As a result of this consultation session, each group was required to submit a Stakeholder Consultation memo where they discussed the issues brought forward by the stakeholders and how they are going to address them in their design

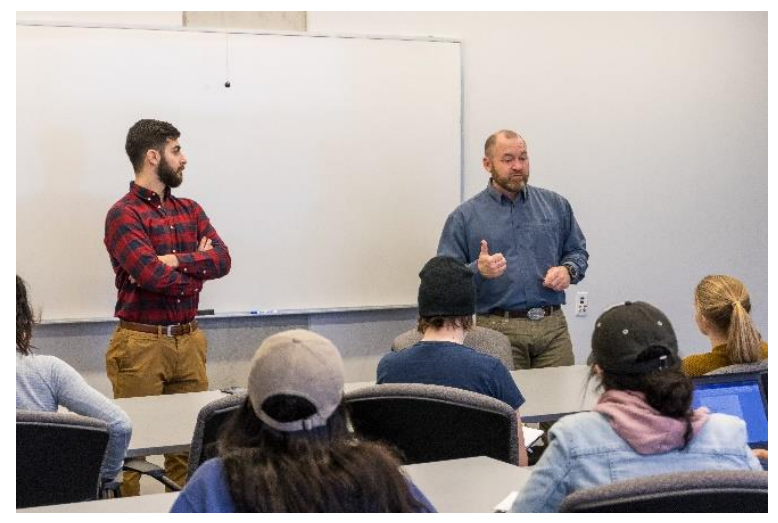

Figure 2: Students engaged in a 'townhall-style' meeting with consulting engineers 
Once the stakeholder consultation was complete the students continued the design process, working collaboratively with others in their group as well as receiving expert advice from professors, TAs and local consultants on the design process. This included statistical analysis of flow data, mechanics of dam stability, hydraulic design of flow conveyance, power generation calculation as well as an analysis and optimization of the cost of the dam. The students were presented with the option of combining hydroelectric power with diesel power generation, and it was up to them to optimize the size of their dam in according to costs, both economic and environmental.

On the $2^{\text {nd }}$ day of the event, the students constructed the valley contours out of polyethylene foam, followed by the earthen dam out of sand and clay. A photo of some of the students during construction can be seen below in Figure 3.

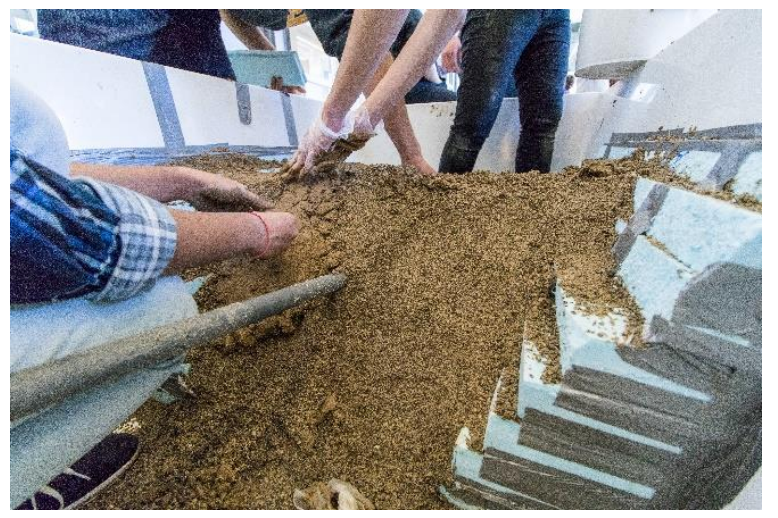

Figure 3: Construction of the dam on Day 2

The dams were then tested using the real-world scenario of having a full reservoir with a flood coming from upstream. The reservoir was filled and then drained to simulate rapid-draw-down in anticipation of the flood. The reservoir was then filled rapidly, including overtopping of the dam to use the designed emergency spillway.

\section{Results}

A survey of the students following the event provided insight into the students' perspective of the event. $87 \%$ of students stated they would participate in another event similar to this while $84 \%$ stated, through the design day, they were able to explore creative solutions to the problem at hand. Importantly, $68 \%$ of students agreed that having two days off to participate in the design days helped decrease their stress.

The main goals of the $2^{\text {nd }}$ Year environmental and geological engineering design days included increasing student understanding of environmental and geological engineering, connecting academic courses with practical experience, and creating a positive environment for creativity and learning. These goals were generally met based on the above statistics as well as the comments submitted with the survey. Comments surrounding the student's favourite part of the design days included "The ability to be creative and fail", "Fun, nice being able to explore designs, take time to understand concepts and calculations without being afraid of the design failing" and "As a group we acted as engineers in real life to help the environment".

Improvements for the next event for the $2^{\text {nd }}$ year environmental and geological engineering students included making the handouts and problem statement clearer while incorporating more concepts from their current classes in the problem. This is exemplified as when asked "I feel that EnvE and GeoE Design Days can be improved by" student responded with comments such as "clearer instructions and expectations", "clearer instructions" and "More clear instructions \& initial presentation of idea/topic". In addition to these comments, over $97 \%$ of students stated this design day helped them understand the applicability of Fluid Mechanics however, only $7 \%$ of students stated it helped them understand the applicability of Environmental Chemistry. Finally, only $44 \%$ of students stated the design days helped motivate them with regards to their current courses. The next event will attempt to remedy this by incorporating more concepts from courses such as Environmental Chemistry or Calculus.

\section{Conclusions}

The Design Day concept has been run in multiple different forms for both the Civil engineering students as well as the environmental and geological engineering students. These events provide a nonjudgemental, collaborative environment for students to connect course concepts with practical skills. The nongraded portion of the design days encourages creative thought without the consequences of failure. Moving forward, a design day event will be run for the $1^{\text {st }}$ year student in environmental and geological engineering to introduce them to some of the concepts they will be studying in the future with the hope of decreasing the transfer rate.

\section{Acknowledgements}

The authors are grateful to the help of Darynne Hagen, Grant Mitchell, Hannah Murphy and Terry Ridgway for their assistance planning and running the 
environmental and geological Engineering Design Day Event. The authors would also like to acknowledge the department of Civil and Environmental Engineering at University of Waterloo (UW), the Centre for Teaching Excellence (CTE) at UW and the IDEAS Clinic at UW for funding and supporting the design days.

\section{References}

[1] Kyle D. Balkos, Benjamin Dow, Shoeleh Shams, Rania Al-Hammoud, Monika B. Emelko, Scott Walbridge and Chris Bachmann "Pedagogical Skill Development Through the Horizontal Integration of a Second-Year Engineering Curriculum" in Proc. ASEE $124^{\text {th }}$ Annual Conference and Exposition (Columbus, OH; June 2017), 14 pp., 2017.

[2] Hollis Duncan and Thomas Dick, "Collaborative Workshops and Student Academic Performance in Introductory College Mathematics Courses; A Study of a Treisman Model Math Excel Program" Collaborative Workshops in College Math, vol. 100, no. 7, pp. 365373, 2000. Available as of April 27, 2018

[3] I. Ivkovic, T. L. Willet, M. J. Borland, M. Gorbet, "Design Days Boot Camp: Enhancing Student Motivation to Start Thinking in Engineering Design Terms in the First Year", in Canadian Engineering Education Association Conference, Toronto, 2017.
[4] K. McKay, S. Mohamed, L. Stacey, "Concepts Only Please! Innovating a First Year Engineering Course", in Canadian Engineering Education Association Conference, Halifax, 2016.

[5] E. Li, C. Rennick, C. Hulls, M. Cooper-Stachowsky, E. Boghaert, M. Robinson, W. Melek, S. Bedi, "Tron Days: Horizontal Integration and Authentic Learning", in Canadian Engineering Education Association Conference, Toronto, 2017.

[6] Stephen Phillips, Kayleanna Giesinger, Rania AlHammoud, Scott Walbridge and Chris Carroll, "Enhancing Student Learning by Providing a Risk Free Environment and Experiential Learning Opportunities" $"$ in Proc. ASEE $125^{\text {th }}$ Annual Conference and Exposition (Salt Lake City, UT; June 2018), 12 pp., 2018.

[7] Michelle D. Repice, R. Keith Sawyer, Mark C. Hogrebe, Patrick L. Brown, Sarah B. Luesse, Daniel J. Gealy, and Regina F. Frey, "Talking through the problems: a study of discourse in peer-led small groups" Chem. Educ. Res. Pract., vol. 17, 2016. Available as of April 27, 2018

[8] Glenn Whitman and Mariale Hardimann, "Assessment and the Learning Brain" Independent Teacher. Available as of April 27, 2018 